\title{
G protein-coupled receptor kinase 3 modulates mesenchymal stem cell proliferation and differentiation through sphingosine-1-phosphate receptor regulation
}

Jaime M. Brozowski ${ }^{1,2,3}$, Roman G. Timoshchenko², D. Stephen Serafin², Brittney Allyn²,3, Jessica Koontz², Emily M. Rabjohns ${ }^{3}$, Rishi R. Rampersad ${ }^{3}$, Yinshi Ren ${ }^{4}$, Amanda M. Eudy ${ }^{3}$,Taylor F. Harris ${ }^{5}$, David Abraham ${ }^{5}$, Daniel Mattox ${ }^{2}$, Clinton T. Rubin ${ }^{6}$, Matthew J. Hilton ${ }^{4}$, Janet Rubin ${ }^{7}$, Nancy L. Allbritton ${ }^{5}$, Matthew J. Billard ${ }^{2}$ and Teresa K. Tarrant ${ }^{1,2,3,8^{*}}$ (1)

\begin{abstract}
Background: The bone marrow niche supports hematopoietic cell development through intimate contact with multipotent stromal mesenchymal stem cells; however, the intracellular signaling, function, and regulation of such supportive niche cells are still being defined. Our study was designed to understand how G protein receptor kinase 3 (GRK3) affects bone marrow mesenchymal stem cell function by examining primary cells from GRK3-deficient mice, which we have previously published to have a hypercellular bone marrow and leukocytosis through negative regulation of CXCL12/CXCR4 signaling.

Methods: Murine GRK3-deficient bone marrow mesenchymal stromal cells were harvested and cultured to differentiate into three lineages (adipocyte, chondrocyte, and osteoblast) to confirm multipotency and compared to wild type cells. Immunoblotting, modified-TANGO experiments, and flow cytometry were used to further examine the effects of GRK3 deficiency on bone marrow mesenchymal stromal cell receptor signaling. Microcomputed tomography was used to determine trabecular and cortical bone composition of GRK3-deficient mice and standard ELISA to quantitate CXCL12 production from cellular cultures.
\end{abstract}

Results: GRK3-deficient, bone marrow-derived mesenchymal stem cells exhibit enhanced and earlier osteogenic differentiation in vitro. The addition of a sphingosine kinase inhibitor abrogated the osteogenic proliferation and differentiation, suggesting that sphingosine-1-phosphate receptor signaling was a putative G protein-coupled receptor regulated by GRK3. Immunoblotting showed prolonged ERK1/2 signaling after stimulation with sphingosine-1-phosphate in GRK3-deficient cells, and modified-TANGO assays suggested the involvement of $\beta$-arrestin-2 in sphingosine1-phosphate receptor internalization.

*Correspondence: Teresa.tarrant@duke.edu

${ }^{8}$ School of Medicine, Duke University, 152 Edwin L. Jones Building, 207

Research Drive, Durham, NC 27710, USA

Full list of author information is available at the end of the article

(c) The Author(s) 2022. Open Access This article is licensed under a Creative Commons Attribution 4.0 International License, which permits use, sharing, adaptation, distribution and reproduction in any medium or format, as long as you give appropriate credit to the original author(s) and the source, provide a link to the Creative Commons licence, and indicate if changes were made. The images or other third party material in this article are included in the article's Creative Commons licence, unless indicated otherwise in a credit line to the material. If material is not included in the article's Creative Commons licence and your intended use is not permitted by statutory regulation or exceeds the permitted use, you will need to obtain permission directly from the copyright holder. To view a copy of this licence, visit http://creativecommons.org/licenses/by/4.0/. The Creative Commons Public Domain Dedication waiver (http://creativeco mmons.org/publicdomain/zero/1.0/) applies to the data made available in this article, unless otherwise stated in a credit line to the data. 
Conclusions: Our work suggests that GRK3 regulates sphingosine-1-phosphate receptor signaling on bone marrow mesenchymal stem cells by recruiting $\beta$-arrestin to the occupied GPCR to promote internalization, and lack of such regulation affects mesenchymal stem cell functionality.

Keywords: Bone marrow-derived mesenchymal stem cells, Mesenchymal stem cells, G protein-coupled receptors (GPCRs), G protein-coupled receptor kinase 3 (GRK3), Sphingosine-1-phosphate (S1P), Sphingosine-1-phosphate receptor (S1PR), Osteogenic differentiation, Proliferation

\section{Introduction}

Mesenchymal stem cells are multipotent stromal cells that possess the ability to differentiate into mesodermal tissues, such as chondrocytes, adipocytes, and osteocytes [1]. Mesenchymal stem cells that reside within the bone marrow microenvironment are often referred to as bone marrow niche mesenchymal stem cells (BmMSCs), secrete high levels of chemokine C-X-C Motif Chemokine Ligand 12 (CXCL12), which can bind to $\mathrm{G}$ protein-coupled receptor (GPCR) C-X-C Chemokine Receptor Type 4 (CXCR4) on hematopoietic stem and progenitor cells (HSPCs) to affect their growth and development $[2,3]$. We previously published that mice deficient in $G$ protein-coupled receptor kinase 3 (Grk3), an intracellular kinase that negatively regulates GPCRs, have a hypercellular bone marrow comprised of increased Lin- Sca1 + c-Kit + (LSK) HSPCs and selective downstream committed progenitors and an increase of total white blood cells in the peripheral blood (leukocytosis) compared to wildtype (WT) mice [4]. GRK3 deficiency affects CXCR4 regulation on hematopoietic cells in mice [4] and humans [5]; however, the regulatory effects of GRK3 on BmMSC function and BmMSC GPCRs are not well defined. Due to the importance of BmMSCs on HSPC biology, we wished to better clarify how GRK3, which is expressed in BmMSCs [6], affects their function and through which GPCR these effects may be regulated.

We observed Grk3-/- BmMSCs have enhanced osteogenic differentiation, higher levels of CXCL12, and increased proliferation. Although we have previously published that global deficiency of GRK3 leads to bone marrow hypercellularity and leukocytosis in mice [4], microcomputed tomography $(\mu \mathrm{CT})$ of cortical and trabecular bone did not show substantial clinical differences in bone density measurements. Accumulating evidence supports that phospholipid sphingosine-1-phosphate (S1P) affects mesenchymal stem cell function [7] in osteogenic differentiation [8-10] and proliferation [11, 12]; thus, we examined GRK3-dependent S1PR antagonism, signaling, and $\beta$-arrestin- 2 recruitment to determine the interplay between these protein interactions in BmMSC biology. Establishing functional relationships in chemokine receptor signaling of stem cells relevant to the bone marrow niche may further facilitate mechanistic understanding of stem cell biology and potential therapeutic targeting of stem cells for the treatment of cancer, autoimmunity, and immunodeficiency disorders.

\section{Materials and methods \\ Animals}

C57BL/6 WT and Grk3-/- age-matched (8-12-weekold) mice were used under standard IACUC-approved protocols in the AAALAC-accredited vivarium of UNC, and care of animals was in accordance with institutional guidelines. The Grk3-/- mouse strain was provided by Dr. Robert J. Lefkowitz (Duke University) and backcrossed $>12$ generations on the C57BL/6 background. The line is re-derived every $1-2$ years to prevent genetic drift from the C57BL/6 strain.

\section{Bone marrow-derived mesenchymal stem cell isolations}

BmMSC were isolated from RPMI-flushed femurs and tibias of two male mice and isolated in complete isolation media (CIM) containing RPMI (Corning, 10-040-CV) with $10 \%$ fetal bovine serum (FBS, Atlanta Biologicals, S12450), 10\% horse serum (HS, HyClone, SH30074.03), $1 \% 100 \mathrm{IU} / \mathrm{mL}$ penicillin $\mathrm{G} / 100 \mu \mathrm{g} / \mathrm{mL}$ streptomycin (P/S, Corning, 30-002-Cl), and $12 \mu \mathrm{M}$ final concentration of L-Glutamine (Corning, 25-005-Cl), as similar methodologies have been previously described [13-15]. Once BmMSC were isolated, the cells were plated and cultured for expansion in complete expansion media (CEM) containing IMDM (Gibco, 12440-053), 10\% FBS, 10\% HS, 1\% $\mathrm{P} / \mathrm{S}$, and $12 \mu \mathrm{M}$ final concentration of L-Glutamine [14, 15], which was followed by hematopoietic CD45 (Stem Cell Technologies, 19771) and CD11b (Miltenyi, 130049-601 or 130-093-634) depletion, as recommended by [13], via magnetic negative selection at early passages $1-3$. BmMSCs were passaged at $70-80 \%$ confluency. The majority of experiments were performed at passages $10-13$ and are specified throughout the manuscript.

\section{Chondrogenic, adipogenic, and osteogenic differentiation Chondrogenic differentiation. BmMSCs were suspended in CEM at $1.6 \times 10^{7}$ viable cells $/ \mathrm{mL}$. Micromasses were made by adding $5 \mu \mathrm{L}$ droplets of the cell suspension onto a 6-well plate and given 3-4 h to attach. Chondrogenic media (Gibco StemPro ${ }^{\circledR}$ Chondrogenesis Differentiation}


Kit, A10071-01) supplemented with penicillin streptomycin was added to each well and incubated for 21 days. Cells were fixed with $10 \%$ formalin and stained using Alcian Blue. Adipogenic differentiation. BmMSCs were plated at $1 \times 10^{5}$ cells/well of a 6-well plate in CEM supplemented with $50 \mu \mathrm{M}$ indomethacin, $5 \mu \mathrm{g} / \mathrm{mL}$ insulin, and $0.1 \mu \mathrm{M}$ dexamethasone. Cells were fixed with $10 \%$ formalin and stained using Oil Red O. Osteogenic differentiation. BmMSCs were plated at $1 \times 10^{5}$ cells/well of a 6-well plate in CEM supplemented with $50 \mu \mathrm{g} / \mathrm{mL}$ ascorbic acid and $20 \mathrm{mM}$ B-glycerophosphate. Cells were fixed with $10 \%$ formalin and stained using Alizarin Red. For sphingosine kinase inhibitor (SKI)-treated osteogenic differentiation, BmMSCs were plated at $2 \times 10^{4}$ cells/well in a 24-well plate in CEM, and osteogenic differentiation was induced after an overnight rest. Cells were treated with sphingosine kinase inhibitor 2 (SKI, Cayman Chemical, 10009222) at a final concentration of $5 \mu \mathrm{M}$ or vehicle (DMSO). Fresh media changes occurred every third day using CEM plus SKI or vehicle. Cells were fixed with $10 \%$ formalin and stained using Alizarin Red stain for analysis. Images were captured using the Olympus 1X-81 microscope and MetaMorph software.

\section{Bone marker mRNA expression (qRT-PCR)}

Total RNA from BmMSCs undergoing osteogenic differentiation was prepared using the RNeasy Mini/ Plus kit (Qiagen) according to manufacturer's instructions. Reverse transcriptase cDNA synthesis was performed using iScript cDNA synthesis kit (Bio-Rad, 170-8891). qRT-PCR was performed in duplicate $\left(\mathrm{SYBR}^{\circledR}\right.$ Green, Bio-Rad, 172-5261) and normalized to housekeeping gene IDUA. Mean fold change of the following markers listed by primers below were determined by $-2 \Delta \Delta \mathrm{Ct}$ with WT day 0 as control. Primers utilized for qRT-PCR were Alkaline Phosphatase forward: AAG GCT TCT TCT TGC TGG TG, Alkaline Phosphatase reverse: GCC TTA CCC TCA TGA TGT CC; Osteocalcin forward: CTG ACC TCA CAG ATC CCA AGC, Osteocalcin reverse: TGG TCT GAT AGC TCG TCA CAA G; Osteopontin forward: AGC AAG AAA CTC TTC CAA GCA A, Osteopontin reverse: GTG AGA TTC GTC AGA TTC ATC CG; Osteonectin forward: GTG GAA ATG GGA GAA TTT GAG GA, Osteonectin reverse: CTC ACA CAC CTT GCC ATG TTT; Osterix forward: AGC GAC CAC TTG AGC AAA CAT, Osterix reverse: GCG GCT GAT TGG CTT CTT CT; IDUA forward: GCA TCC AAG TGG GTG AAG TT and IDUA reverse: CAT TGA GCA GGT CCG GAT AC.

\section{ELISA}

BmMSCs were plated at $1 \times 10^{5}$ cells/well of a 6 -well plate in CEM and rested overnight for attachment before supernatant collections began at baseline (day 1) and each subsequent collection. Supernatants of undifferentiated BmMSC monolayers were collected and analyzed for CXCL12 protein using the CXCL12 DuoSet ELISA kit (R\&D Systems, DY460), as per instructions.

\section{Microcomputed tomography $(\mu \mathrm{CT})$}

For 8-12-week-old mice, $\mu \mathrm{CT}$ imaging was used to analyze the trabecular bone morphology at the distal femur at 12 micron resolution. The metaphyseal region of the distal femur was scanned beginning 720 microns proximal to the growth plate and extending 1500 microns toward the diaphysis of the femur. An automatic script was used to analyze the region of interest to separate the trabecular and cortical regions of the bone and quantify bone morphology. Trabecular analysis includes quantification of BV/TV (bone volume/total volume). For 17-20-month-old aged mice, $\mu \mathrm{CT}$ imaging morphology (VivaCT80, Scanco Medical, Basserdorf, Switzerland) was used to analyze the trabecular bone. Briefly, metaphysis region was selected for 100 slices under the femur growth plate. Trabecular analysis includes quantification of BV/TV. Analyses were conducted at $12 \mu \mathrm{m}$ slice increment with an integration time of $300 \mathrm{~ms}$, a current of $145 \mathrm{~mA}$, and an energy setting of $55 \mathrm{kV}$. The threshold was chosen using $2 \mathrm{D}$ evaluation of several slices in the transverse anatomic plane so that mineralized bone was identified but surrounding soft tissue was excluded.

\section{Cellular proliferation}

Proliferation of $5 \times 10^{4} \mathrm{BmMSCs} /$ well of a 6 -well plate was analyzed after exogenous CCK-8 (Dojindo Molecular Technologies) was added to each well at the indicated timepoints. Absorbance was measured after $3 \mathrm{~h}$ incubation using the Promega Glomax ${ }^{\circledR}$ Multi+Detection System. Data were analyzed by deducting background (media and CCK-8) absorbance from raw absorbance reads. For S1P studies, BmMSCs were plated at $1 \times 10^{4}$ cells/well in a 24-well plate and treated with SKI at a final concentration of $5 \mu \mathrm{M}$.

\section{CXCL12 per cell measurement}

To quantify CXCL12 production per BmMSC, cells were plated at 9,374 cells/cm2 and cultured for 5 days in CEM. On day 5 , supernatants were collected, cells were washed with $\mathrm{PBS}$ prior to trypsinization, and live cells were counted using trypan blue exclusion. A CXCL12 ELISA (Sigma, St. Louis, MO, USA) was used to determine the concentration of CXCL12 in the culture supernatant, which was then divided by the number of cells in that well to obtain the amount of CXCL12 secreted per cell. 


\section{Immunoblotting}

BmMSCs were plated in CEM at $2.25 \times 10^{5}$ cell density in a 6-well plate and incubated overnight. DPBS rinsed cells were rinsed three times with IMDM containing $20 \%$ charcoal-stripped FBS (to remove serum S1P) and $1 \% \mathrm{P} / \mathrm{S}$ and incubated at $37{ }^{\circ} \mathrm{C}$ for $15 \mathrm{~min}$. Fresh media was added, and BmMSCs were stimulated with $1 \mu \mathrm{M}$ S1P for indicated timepoints. Unstimulated BmMSCs served as 0 min timepoint control. Following stimulation with S1P, BmMSC cells were rinsed with DPBS and lysed in cold HBSS $+1 \%$ TritonX100 lysis buffer containing protease inhibitors ( $1 \mathrm{mM}$ PMSF, $1 \mu \mathrm{g} / \mathrm{mL}$ aprotinin, $1 \mu \mathrm{g} / \mathrm{mL}$ pepstatin, and $1 \mu \mathrm{g} / \mathrm{mL}$ leupeptin) and phosphatase inhibitors (5 mM NaF and $\left.2 \mathrm{mM} \mathrm{NaVO}_{4}\right)$. All WT and Grk3-/- BmMSC lysates were normalized via bicinchoninic acid (BCA) assay, and $6 \mu \mathrm{g}$ of total protein in Laemmli sample buffer (non-reducing) was freshly loaded onto AnyKD Mini-PROTEAN ${ }^{\circledR}$ TGX precast protein gel (Bio-Rad, 4569036). Gels were run at $100 \mathrm{~V}$ for $1.5-2 \mathrm{~h}$ in $1 \mathrm{X}$ Tris/Glycine SDS buffer. Proteins were transferred overnight at $4{ }^{\circ} \mathrm{C}$ onto nitrocellulose membrane in Tris base $(25 \mathrm{mM}) /$ Glycine $(192 \mathrm{mM})$ transfer buffer containing 20\% methanol. The membrane was blocked in 3\% fatty-acid free BSA in TBS plus $0.1 \%$ Tween-20 (TBS/T) for $2 \mathrm{~h}$ at $25{ }^{\circ} \mathrm{C}$ and incubated with primary antibody 1:2,000 phospho-p44/42 MAPK or 1:2,000-3,000 p44/42 MAPK (Cell Signaling Technologies, $4370 / 4695)$ overnight at $4{ }^{\circ} \mathrm{C}$, or $1: 10,000 \mathrm{GAPDH}$ (Trevigen, 2275-PC-100) for $2 \mathrm{~h}$ at $4{ }^{\circ} \mathrm{C}$. The membrane was washed three times for $10 \mathrm{~min}$ in TBS/T, incubated with secondary antibody 1:5,000 anti-rabbit IgG HRP (Cell Signaling Technologies, 7074) for $1 \mathrm{~h}$ at $25^{\circ} \mathrm{C}$, and washed twice for $10 \mathrm{~min}$ in TBS/T and once in TBS. Detection was performed via ECL Prime or ECL Select (GE Healthcare, RPN2232/ RPN2235) and imaged on GeneSys image acquisition software. Densitometry was obtained by measuring ratio of phospho-ERK (pERK) over total ERK using ImageJ software.

\section{$\beta$-arrestin recruitment assay}

GRK recruitment of $\beta$-arrestin-2 to the S1PR1 carboxyterminus was measured using agonist-stimulation in a modified-TANGO assay, as previously reported [16]. HTLA cells were transfected with a S1PR1-TCS-tTA receptor construct after removing the $\mathrm{V} 2$ vasopressin sequence to prevent nonspecific $\beta$-arrestin recruitment to the wildtype S1PR1. GRK overexpression was achieved via plasmids: GRK2 pcMyc_LIC and GRK3 pcMyc_LIC, and utilized a separate expression vector encoding yellow fluorescent protein (YFP) that was simultaneously transfected to serve as a transfection control. HTLA cells were transiently transfected with $6.5 \mu \mathrm{g}$ of total plasmid DNA (3 $\mu \mathrm{g}$ of S1P-Tango, $0.5 \mu \mathrm{g}$ of YFP, and either
$3 \mu \mathrm{g}$ of empty-vector control, GRK2, or GRK3) via calcium-phosphate precipitation. Transfection efficiency was determined by YFP epifluorescence to be consistently $>70 \%$ at $24 \mathrm{~h}$ post-transfection. Cells were serum starved and then stimulated with S1P ligand at varied concentrations up to $1 \mu \mathrm{M}$. BriteGlo reagent (Promega, Madison, WI, USA) was added for luminescence detection via Promega Glomax ${ }^{\circledR}$ Multi + Detection System $(0.5 \mathrm{~s} /$ well). Raw data were normalized by subtracting background for each independent run and setting the lowest concentration of the control condition at $0 \%$ and highest concentration at $100 \%$.

\section{S1PR1 internalization assay}

BmMSCs cultured in CEM were rinsed with DPBS and incubated in serum-free CEM (SFM) for $2.5 \mathrm{~h}$. BmMSCs were detached using Accutase ${ }^{\circledR}$ (Sigma, A6964), rinsed once with cold SFM containing 5\% charcoal-stripped FBS (to remove serum S1P), and resuspended in cold DPBS. $1 \times 10^{5}$ BmMSCs were stimulated with $1 \mu \mathrm{M}$ S1P ligand in $100 \mu \mathrm{L}$ FACS buffer (DPBS1X $+0.2 \%$ fatty acid free $\mathrm{BSA}+0.1 \%$ sodium azide) at specific timepoints. Unstimulated BmMSCs served as 0 min timepoint control. S1PR1 internalization was halted with $2 \mathrm{~mL}$ of ice cold FACS buffer and sample tubes were placed on ice. BmMSCs were stained for Scal (eBioscience clone: D7, APC-conjugated) and S1PR1 (R\&D Systems clone: 713,412, PE-conjugated) for $30 \mathrm{~min}$ on ice in $100 \mu \mathrm{L}$ FACS Buffer, rinsed, and analyzed by flow cytometry.

\section{Statistical analyses}

All data were graphed utilizing GraphPad Prism v.7 and statistically evaluated using GraphPad Prism v.7 or Microsoft Office Excel program. Taking into consideration time and strain (WT and Grk3-/-), the bone marker qRT-PCR, CCK-8 proliferation, and S1PR1 internalization was statistically analyzed using a RM two-way ANOVA with Sidak's multiple comparison test, a method preferred over Bonferroni due to increased power [17, 18]. Similarly, taking into consideration time and strain (WT and Grk3-/-) but with multiple treatment groups, the SKI-treated CCK-8 proliferation was analyzed using a RM two-way ANOVA with Tukey's multiple comparison test for pairwise comparisons [17, 19]. Student's t-test compared two independent groups (WT and Grk3-/-) for the CXCL12-detection ELISA, microcomputed tomography data, qRT-PCR of bone markers, and western blot densitometry. Taking into consideration three independent groups (empty vector, GRK2, and GRK3), the $\beta$-arrestin recruitment assay was analyzed by one-way ANOVA with Dunnett's multiple comparison test, which compared each group to the control (empty vector) [17, 20]. 


\section{Results}

\section{GRK3-deficient BmMSCs have enhanced osteogenic} differentiation

In our previous publication, we observed Grk3-/- mice had increased HSPC numbers compared to WT mice [4]. Since it is well established that bone marrow stromal cells enhance hematopoiesis [21-26], we aimed to test whether there were differences between Grk3/- and WT murine stromal BmMSCs that could contribute to this phenotype. BmMSCs isolated from WT and Grk3-/- mice adhered to culture plastic, underwent differentiation into tissue-specific lineages to ensure multipotency (Fig. 1A), and lacked expression of CD45 and CD11b (hematopoietic cell markers) and expressed mouse mesenchymal stem cell markers Sca1, CD106, CD73, CD44, CD29 (Additional File 1: Fig. S1 and Additional File 2: S2). During differentiation analysis, we observed no substantial differences between WT and Grk3-/- BmMSC chondrogenic or adipogenic differentiation cultures. However, we observed enhanced and earlier osteogenic differentiation in Grk3-/BmMSC cultures in comparison with WT cultures, as demonstrated by positive Alizarin Red stain (Fig. 1B) and higher mRNA expression levels of several markers of osteoblast differentiation over time including alkaline phosphatase, osterix, osteocalcin, and osteonectin (Fig. 2) [27, 28]. We noticed the enhanced osteogenic differentiation phenotype was reproducible in four separate isolations. To further ensure there was no isolation differences between WT and Grk3-/- BmMSCs that may induce such a phenotype, we utilized shRNA to knockdown GRK3 (Grk3-KD) from WT BmMSCs and induced multipotent differentiation, which again showed the identical phenotype of enhanced
A.

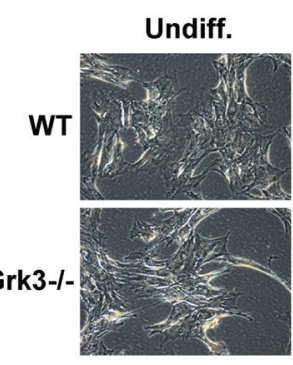

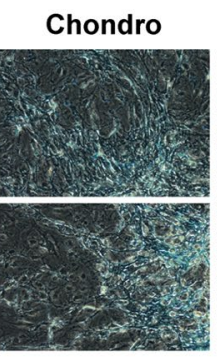

B.

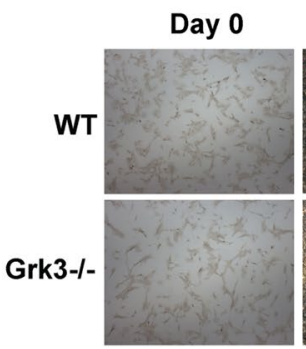

Day 14
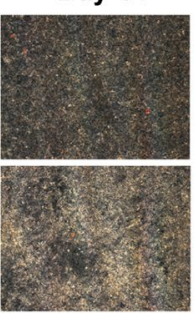

Day 17

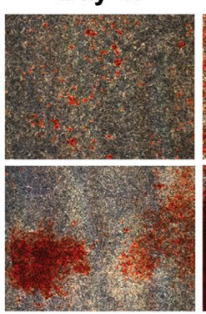

Day 21

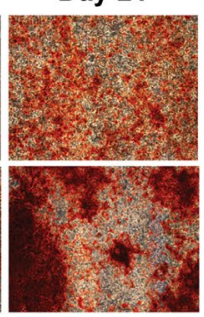

C.
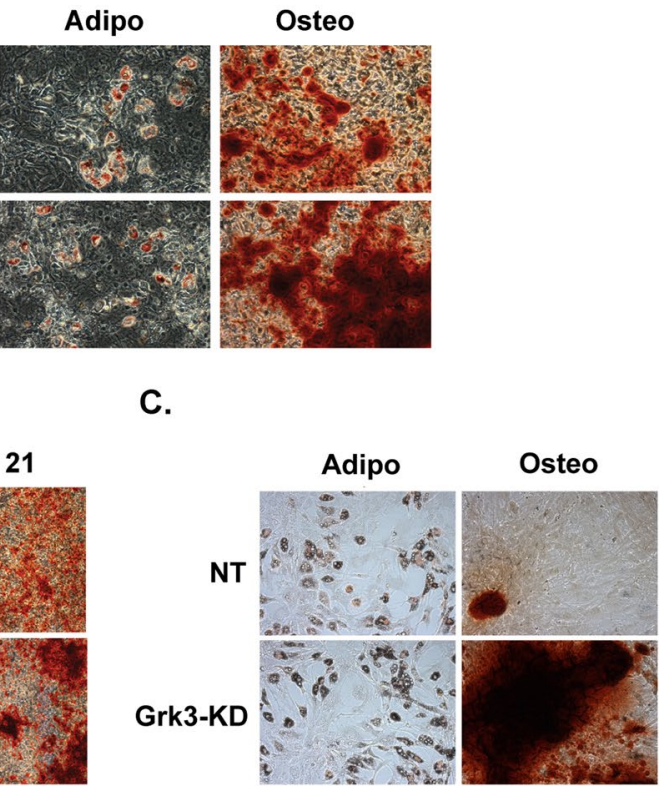

Fig. 1 Bone marrow-derived mesenchymal stem cells (BmMSCs) deficient in G protein-coupled receptor kinase 3 (Grk3-/-) and Grk3-deficient shRNA knockdown BmMSCs have enhanced osteogenic differentiation in comparison with wildtype (WT) or nontarget knockdown (NT) control BmMSCs. (A) Multipotent differentiation of BmMSCs isolated ex vivo from Grk3-/- and WT mice into chondrocytes (Alcian Blue stain), adipocytes (Oil Red O stain), and osteoblasts (Alizarin Red stain) at day 21; images acquired at 10X magnification. Differentiation analyses $n=3$ chondrogenic/ adipogenic and $n=10$ osteogenic, passages 7-11. (B) Time-course Grk3-/- and WT BmMSC osteogenic differentiation (Alizarin Red stain) at 2X magnification. Representative images, $n=4$, passages 10 and 11. (C) shRNA Nontarget (NT) control and GRK3-knockdown (GRK3-KD) BmMSCs have comparable adipogenic differentiation (Oil Red O stain); however, GRK3-KD BmMSCs show enhanced osteogenic differentiation (Alizarin Red stain), similar to BmMSCs isolated from Grk3-/- mice. Images captured at 10X magnification using the Olympus 1X-81 microscope and MetaMorph software

(See figure on next page.)

Fig. 2 Osteogenic expression markers increase in MSC cultures during osteogenic differentiation relative to housekeeping gene IDUA. qRT-PCR of osteogenic differentiation markers alkaline phosphatase, osterix, osteonectin, and osteocalcin from BmMSC ex vivo cultures in osteogenic differentiation media over time (days 0-17). Left panels are comparing Grk3-/- to WT BmMSC cultures ( $n=6$, passages 10-15), and right panels are comparing Grk3-shRNA knockdown to nontarget shRNA control BmMSC cultures $\left(n=4\right.$, passages 11,12). ${ }^{*} P \leq 0.05{ }^{* *} P \leq 0.01$ 


\section{Alkaline Phosphatase}
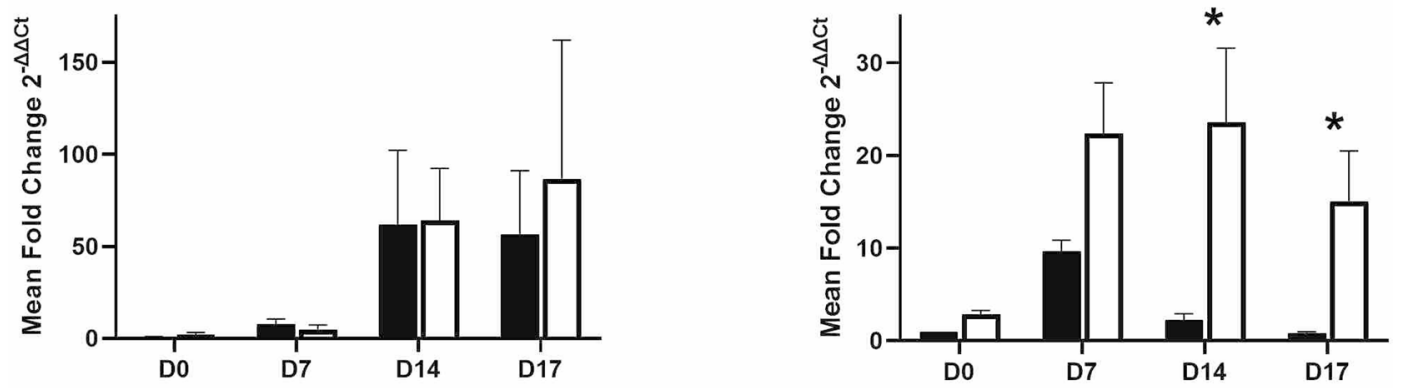

\section{Osterix}
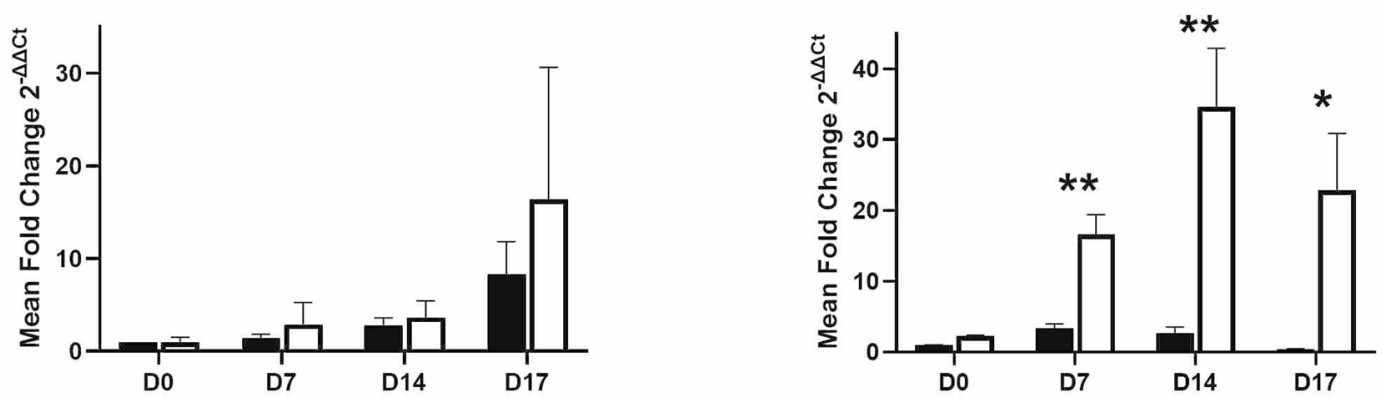

Osteonectin
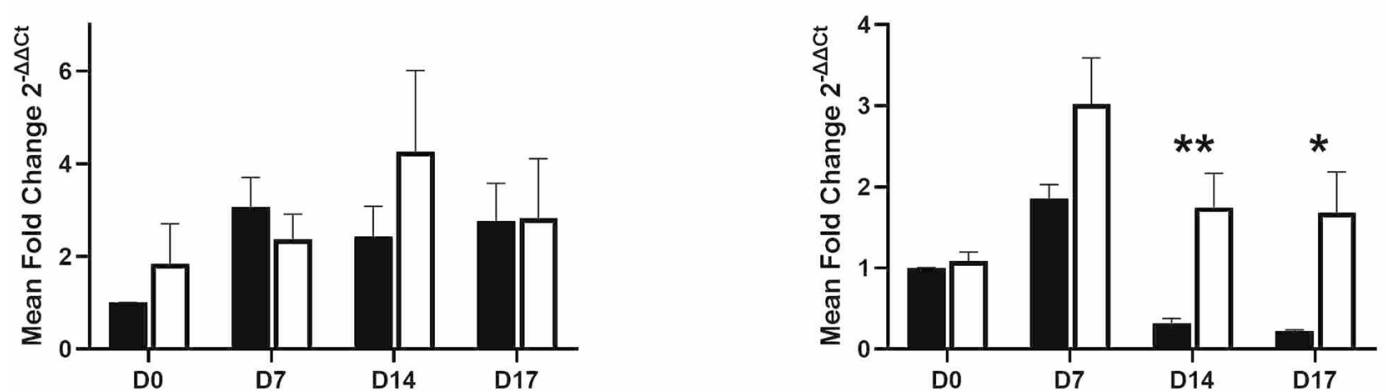

Osteocalcin

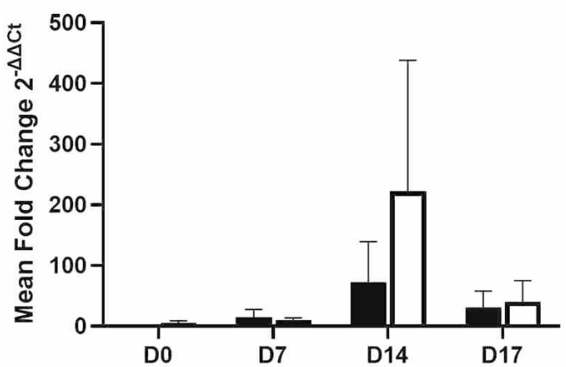

Grk3-/-

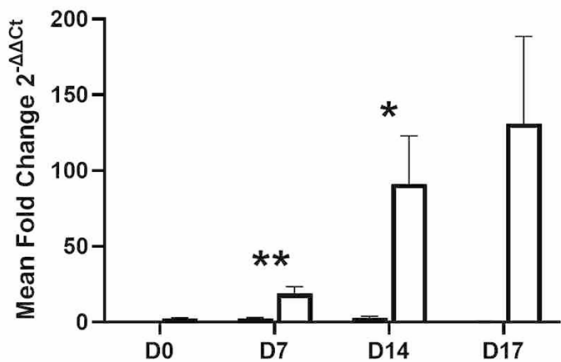

Grk3-KD 
osteogenic differentiation in Grk3-KD BmMSCs in comparison with nontarget (NT) control BmMSCs (Fig. 1C). Osteoblast differentiation marker increases were statistically significant for alkaline phosphatase, osterix, osteocalcin, and osteonectin (Fig. 2). Osteopontin expression levels were detected but not found to be different between Grk3-deficient cultures that were isolated from Grk3-/- mice or as shRNA knockdowns of MSC cultures when compared to controls (data not shown).

\section{GRK3-deficient BmMSC cultures have higher levels of CXCL12 but there is not increased CXCL12 secretion per cell}

BmMSCs, CXCL12-abundant reticular cells, and preosteoblasts isolated from bone marrow secrete CXCL12 [22, 23], an essential chemokine for HSPC development and/or function. Since we published that Grk3-/- mice had increased HSPCs in vivo [4], we tested whether or not there may be differences in HSPC growth factor CXCL12 between WT and Grk3-/- BmMSCs ex vivo. Our data reveal that Grk3-/- BmMSC cultures have higher CXCL12 levels at baseline and after subsequent days in culture in comparison with WT BmMSC (Fig. 3A). However, when CXCL12 was analyzed as a per cell calculation (Fig. 3C), CXCL12 secretion was found to be similar between WT and Grk3-/- MSCs.

\section{GRK3 deficiency increases BmMSC proliferation ex vivo}

Due to the enhanced detection of CXCL12 in Grk3-/BmMSC culture but a CXCL12/cell ratio that was similar between WT and Grk3-/- MSCs, we wanted to further investigate whether this was the result of enhanced Grk3/- MSC proliferation. Cell counting kit-8 (CCK-8) quantitates proliferation by absorbance detection of increased formazan dye production from viable cells. Using this assay of cellular proliferation, we show that Grk3-/BmMSCs have more proliferation in comparison with WT BmMSCs (Fig. 3B).

\section{GRK3 deficiency does not affect mature bone formation in vivo}

Because Grk3-/- BmMSC osteogenic differentiation and proliferation are increased ex vivo, we investigated whether or not GRK3 deficiency affected mature bone development and susceptibility to osteoporosis in vivo. We performed $\mu \mathrm{CT}$ femoral bone analyses on WT and Grk3-/- young (8-12 weeks) and aged (17-20 months) female mice. No statistical differences in the trabecular bone volume fraction of Grk3-/- young or aged female mice were observed between genotypes (Fig. 4A-D).

\section{Inhibition of S1P reduces the enhanced osteogenic differentiation and proliferation phenotype of Grk3-/- BmMSCs}

Since GRK3 regulates signaling of cell-surface expressed GPCRs [6], we next aimed to identify the putative GPCR that could be contributing to the enhanced Grk3-/BmMSC phenotypes of osteogenic differentiation and proliferation. Since we and others have demonstrated that BmMSCs secrete CXCL12 [22, 23], that GRK3 regulates CXCR4 in other cell types [4, 5, 29], and that GRK3 regulation of CXCR4 impacts bone marrow hematopoietic cell functionality $[4,30]$, we hypothesized CXCL12 may be acting via an autocrine CXCL12/CXCR4 signaling loop on BmMSCs. However, neither agonist stimulation nor antagonist inhibition of CXCR4 signaling affected the increased Grk3-/- BmMSCs proliferation that we observed (Additional File 3: Fig. S3).
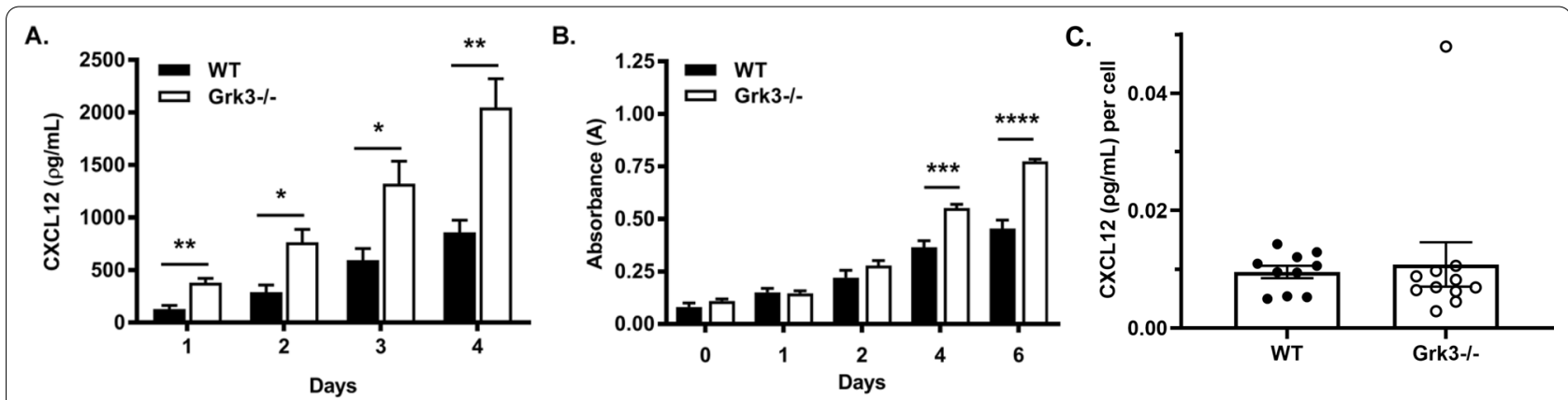

Fig. 3 Grk3-/-BmMSCs have higher levels of CXCL12 detected in culture and proliferate more in comparison with WT BmMSCs but secrete similar amounts of CXCL12 per cell. (A) Quantification of CXCL12 protein concentration from supernatant of BmMSC cultures. Lower limit of detection at $46.9 \mathrm{pg} / \mathrm{mL}$. Data represent mean $\pm \mathrm{SEM}, n=4$, passages 11 and 12. (B) BmMSC proliferation determined by increased formazan dye production from viable cells over time using CCK-8 proliferation assay. Data represent mean \pm SEM, $n=3$, except day $0 n=2$, passage 7 . ${ }^{*} P \leq 0.05 * * P \leq 0.01 * * *$ $P \leq 0.001,{ }^{* * *} P \leq 0.0001$ (C) CXCL12 per MSC determined by trypsinized cell count using trypan blue exclusion of individual wells divided by the amount of CXCL12 (pg/ml) measured by ELISA. Data represent mean \pm SEM, $n=11$ Grk3-/-, $n=10$ WT, passages 10-13 
A.

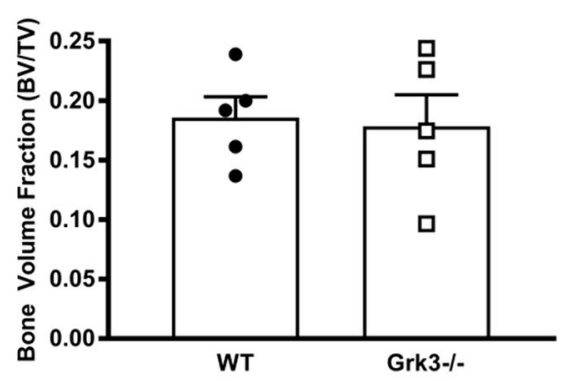

B.

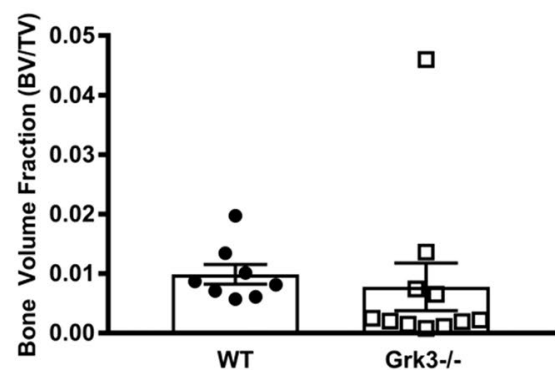

c.

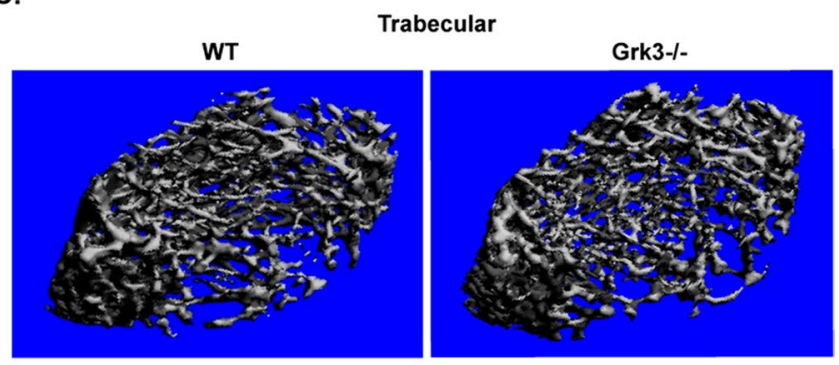

D.

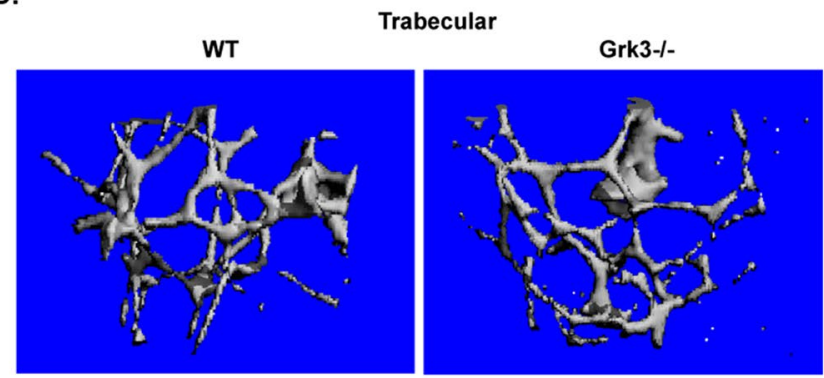

Fig. 4 Femoral trabecular bone density is not differentially affected by GRK3 deficiency in young or aged mice. Quantification of trabecular bone volume fraction (BV/TV) via microcomputed tomography analysis of (A) young and (B) aged Grk3-/- and WT mouse femurs. Representative 3D image of trabecular bone of (C) young and (D) aged Grk3-/- and WT mouse femurs. Data represent mean \pm SEM, $n=5$ for young mice and $n=8$ (WT) $n=11$ (Grk3-/-) for aged female mice

Accumulating evidence supports phospholipid S1P affects mesenchymal stem cell function [7], specifically in osteogenic differentiation [8-10] and proliferation $[11,12]$. Since S1P binds to GPCR S1P receptors (S1PR), we next hypothesized that GRK3 was negatively regulating S1PR signaling, leading to functional outcomes of enhanced BmMSC proliferation and osteogenic differentiation. To test this hypothesis, we had to address that S1P is readily available in the BmMSC culture media due to the naturally high presence in fetal bovine and horse serum [31] and that murine BmMSCs secrete S1P [32], similarly to CXCL12. Therefore, to effectively neutralize S1P in culture, we utilized a sphingosine kinase inhibitor (SKI), which reduces the conversion of sphingosine to active ligand S1P. We also verified that WT and Grk3/- BmMSCs had comparable sphingosine kinase activity before manipulation of this pathway (Additional File 4: Fig. S4). Titration of SKI to an optimized dose of $5 \mu \mathrm{M}$ reduced both Grk3-/- osteogenic differentiation (Fig. 5A) and proliferation (Fig. 5B) to comparable levels with WT BmMSCs, suggesting S1PR, and not CXCR4, has a role in the enhanced phenotypes.
Grk3-/- BmMSCs have enhanced ERK1/2 signaling after S1P stimulation

The extracellular-related kinase (ERK) signaling pathway has been linked to both mesenchymal stem cell [33] and pre-osteoblastic cell line [34] osteogenic differentiation, as well as mesenchymal stem cell proliferation [12]; therefore, we hypothesized ERK signaling may be enhanced in Grk3-/- BmMSCs with S1P stimulation. We show via densitometry ERK1/2 early signaling at 0,1 , and $5 \mathrm{~min}$ is comparable between WT and Grk3-/- BmMSCs (Fig. 6A, B); however, during late signaling, while WT signaling wanes after $30 \mathrm{~min}$, Grk3-/- BmMSCs show sustained signaling still at $60 \mathrm{~min}$ (Fig. 6A, C).

\section{GRK3 recruits $\beta$-arrestin to the C-terminus of S1PR1 and affects S1PR1 internalization}

While BmMSCs express S1PRs 1-3 [35-37], the intracellular signaling, function, and regulation of each specific receptor on BmMSCs is still being defined. Recent studies have shown stimulatory BmMSC function through ligation of S1PR1 and S1PR3 in contrast to inhibition of function after stimulation through S1PR2 [36]. We hypothesized our enhanced GRK3-regulatory 
A.

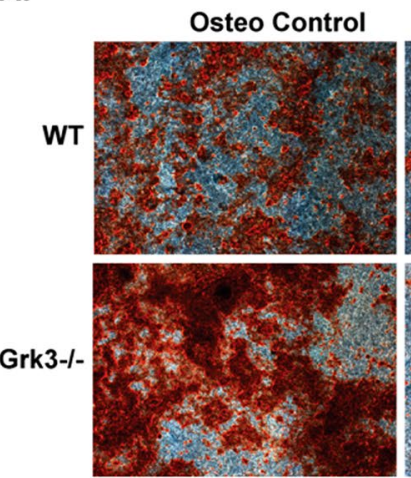

Osteo + SKI
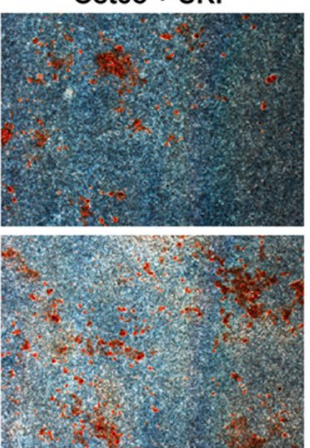

B.

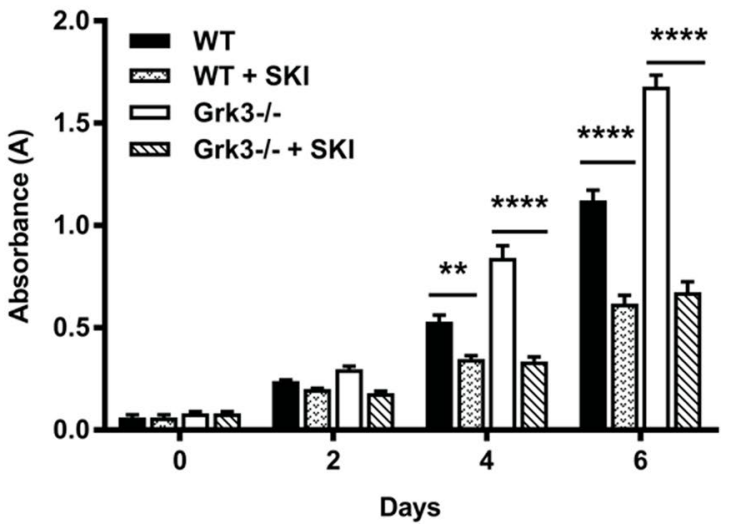

Fig. 5 Osteogenic differentiation and proliferation of Grk3-/- BmMSCs are decreased to WT levels with sphingosine kinase inhibitor treatment. (A) BmMSCs treated with $5 \mu$ M SKI while in osteogenic media for differentiation studies and stained with Alizarin Red. Representative images acquired at $2 \mathrm{X}$ magnification, $n=3,13$, 14. (B) BmMSCs cultured with $5 \mu \mathrm{M}$ SKI in culture media for proliferation detection over time. Data represent mean \pm SEM, $n=3$, passage $11^{* *} P \leq 0.01{ }^{* * *} P \leq 0.0001$

A.

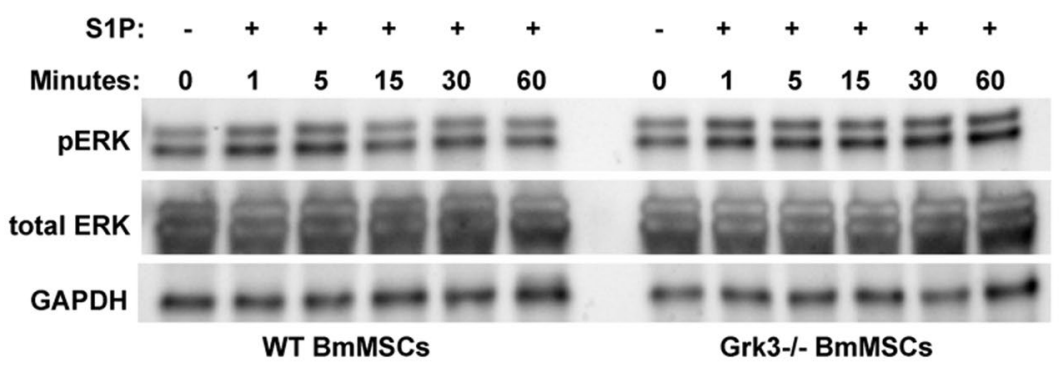

B.

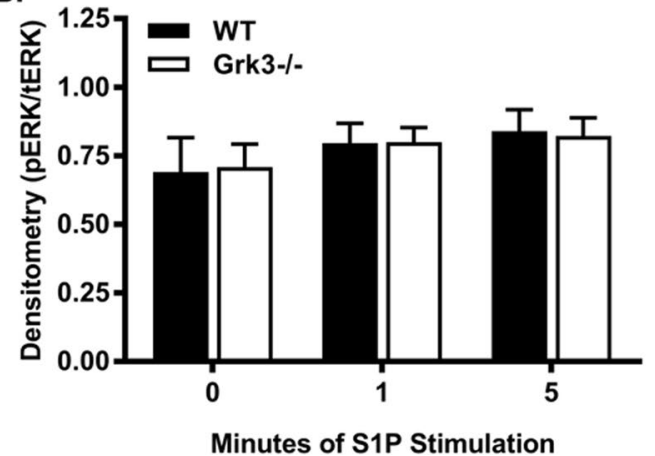

C.

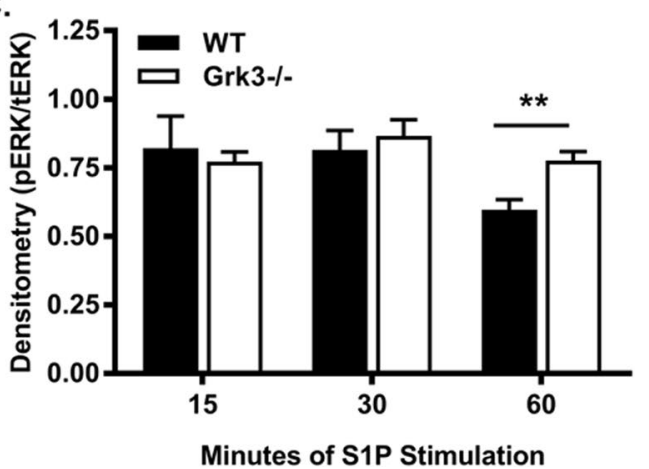

Fig. 6 Grk3-/-BmMSCs have enhanced ERK1/2 signaling after S1P stimulation at later timepoints. (A) WT (left) and Grk3-/- (right) BmMSCs were stimulated with $1 \mu \mathrm{M} \mathrm{S1P}$ for designated times for analysis of ERK1/2 signaling; phospho-ERK (pERK) and total ERK (tERK). Representative blot, $n=4$. The $p E R K / t E R K$ ratio for each blot was quantified via densitometry for (B) early-stage ERK signaling at 0, 1, and 5 min and (C) late-stage ERK signaling at 15,30 , and $60 \mathrm{~min}$. Data represent mean $\pm \mathrm{SEM}, n=4$, passages 13 and $15 .{ }^{* *} P \leq 0.01$

phenotype may be mediated via S1PR1, since our Grk3/- BmMSCs phenotype showed enhanced proliferation and prolonged ERK1/2 signal activation, analogous to previously reported S1PR1 activation in adipose-derived mesenchymal stem cells [12]. S1PR1 was also clearly detected on WT and Grk3-/- BmMSCs by protein lysate analysis and flow cytometry (Additional File 5: Fig. S5A, B). 
We hypothesized that GRK3 could be involved in S1PR1 $\beta$-arrestin recruitment-a protein necessary for GPCR internalization and another pathway of GPCR regulation in addition to receptor desensitization. Using the modified-TANGO assay $[16,38]$ with GRK2 as a positive control [39], we demonstrated GRK3 recruits $\beta$-arrestin to the C-terminus of S1PR1 (Fig. 7A). We next hypothesized that receptor internalization was an additional means of GRK3/S1PR1 regulation, and thus S1PR1 internalization would be impaired in Grk3-/- BmMSCs. In S1P-activated receptor internalization assays, S1PR1 surface receptor expression by flow cytometry was prolonged over time in Grk3-/- BmMSCs compared to controls (Fig. 7B), suggesting a defect in $\beta$-arrestin-mediated internalization.

\section{Discussion}

Mesenchymal stem cells are under active investigation for use in regenerative medicine and cell therapy; therefore, there is an essential need for better cellular characterization and understanding of their signaling, function, and regulation [40-42]. Challenges within the field include ex vivo expansion studies utilizing different tissuederived sources of cells, growth media conditions, serum sources and lots, seeding densities, and sample variations $[40,43]$, which can be potential confounders in interpreting data. To reduce such confounders, we utilized media previously published to best support BmMSCs from C57BL/6 mice [14], maintained the same serum sources and lots throughout all studies, seeded and cultured cells at comparable densities, and minimized sample-variation findings by design and testing of several different BmMSC isolations from WT and Grk3-/- mice. We also performed the majority of experiments at passages 10-13 and have specified specific passages used for experimentation in figure legends.

Our WT and Grk3-/- BmMSC cultures had similar levels of mesenchymal stem cell markers Sca1, CD106, CD44, CD29 (Additional File 1: Fig. S1 and Additional File 2: S2); however, there was some variability of CD73, a marker of multipotency [44], in some batches. The variability was more pronounced in wild type control cultures, albeit this was not statistically significant (Additional File 2: Fig. S2). The variability does highlight the challenge when working with separate BmMSC isolates that can lead to sample variation [40, 43]. Given that the CD73 expression was variable but the phenotypes remained intact between Grk3-/- and WT MSCs batches, we hypothesize that CD73 does not explain the differences we observe between the genotypes in osteogenic differentiation and proliferation.

We observe in Fig. 2 that osteogenic markers were increased over time in both Grk3-/- BmMSC cultures isolated from Grk3-/- mice and in Grk3-deficient shRNA knockdown BmMSCs when compared to control cultures and that this correlates with the earlier and enhanced morphologic osteogenic differentiation observed in culture (Fig. 1). Expression data from the Grk3-/- BmMSCs were not statistically significant, whereas it was statistically significant for alkaline phosphatase, osterix, osteonectin, and osteocalcin at later timepoints in the Grk3-deficient shRNA knockdown cultures. We hypothesize that this may be due to earlier passages that were available for testing the Grk3-KD cultures compared to later passages that were available for the Grk3-/- BmMSCs.

Grk3-/- BmMSC cultures had higher levels of CXCL12 at baseline upon equal seeding densities, and one
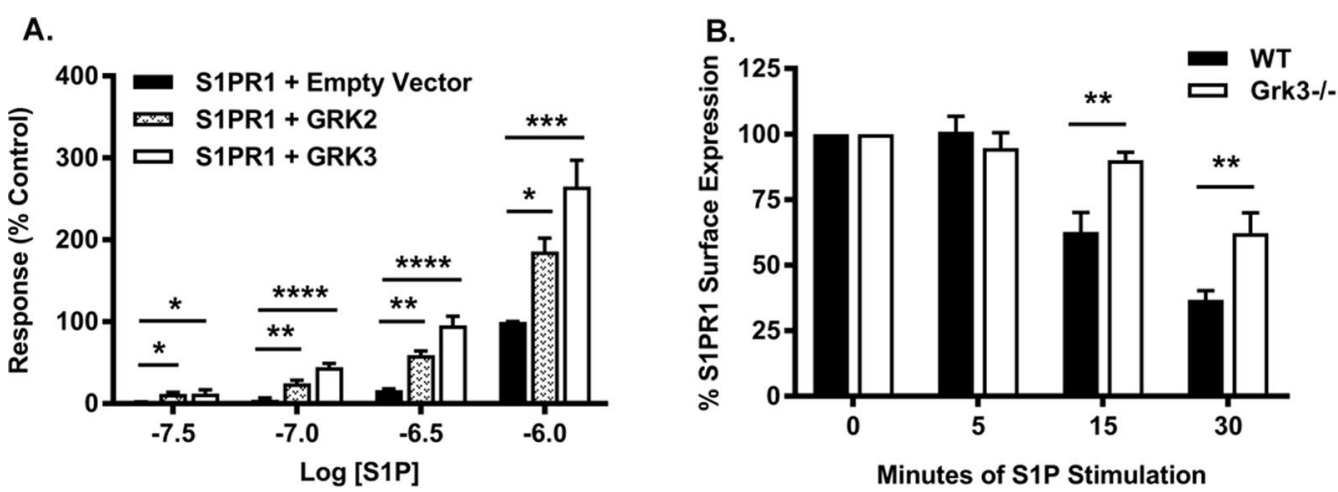

Fig. 7 GRK3 recruits $\beta$-arrestin to the C-terminus of S1PR1 and affects S1PR1 internalization. (A) HTLA cells transfected with S1PR1-TCS-tTA receptor construct and empty vector (negative control), GRK2 (positive control), or GRK3 plasmids and stimulated with $1 \mu$ M S1P for detection of $\beta$-arrestin recruitment response via luminescence. Data represent mean $\pm \mathrm{SEM}, n=6$. (B) Sphingosine-1-phosphate receptor 1 (S1PR1) surface expression as measured by median fluorescence intensity compared to unstimulated cells ( 0 min) by flow cytometry. WT and Grk3-/- BmMSCs were stimulated with $1 \mu \mathrm{M}$ S1P at designated timepoints. Data represent mean \pm SEM, $n=5$, passages $11,12,13$. ${ }^{*} P \leq 0.05{ }^{* *} P \leq 0.01{ }^{* * *} P \leq 0.001{ }^{* * * *} P \leq 0.0001$ 
interpretation is that Grk3-/- BmMSCs could have an enhanced CXCL12 secretory function, such as has been described of CXCL12-abundant reticular stromal cells in the bone marrow [22]. However, our study also detected enhanced proliferation of Grk3-/- BmMSCs (Fig. 3B), and the CXCL12 per cell calculation (Fig. 3C) does not support increased secretory function. This suggests the levels of CXCL12 detection at most timepoints are likely due to the increased number of Grk3-/- BmMSCs in culture.

We hypothesize that these in vitro findings may additionally contribute toward mechanisms underlying the enhanced hematopoiesis phenotype that we observed in the Grk3-/- mouse [4] and appear to be less relevant in osteoporosis or mature bone development (Fig. 4). Previous studies have demonstrated depletion of CXCL12 or total numbers of mesenchymal stem cells decrease the bone marrow hematopoietic stem cell pool and repopulating activity [22-24]. Thus, we might conclude the enhanced numbers of HSPCs observed in the Grk3-/- mouse bone marrow [4] could be attributed at least in part to the Grk3-/- BmMSC-enhanced phenotypes described here. However, we recognize that selective Grk3 gene targeting of mesenchymal stem cells and/ or osteoblasts in vivo would be necessary to definitively conclude this - the timing of which may prove challenging in targeting which stage of stem cell development is most relevant for Grk3 expression. These are the goals of future studies, as opposed to the focus of this initial characterization of Grk3-/- BmMSCs and identification of candidate regulatory GPCRs.

Neither young (8-12-week-old) nor aged (17-20-month-old) Grk3-/- mice show enhancement of mature trabecular bone formation in vivo (Fig. 4A-D). Possible explanations of this finding may be attributed to our Grk3-/- conventional knockout mouse model, where there may be other compensatory cellular interactions at play. Importantly, Grk3 expression levels have been found to be either undetectable or minimally expressed in osteoblastic cell lines [45]. This physiologic downregulation of Grk3 in more mature osteoblasts, as opposed to precursor stem cells, could also explain why differences were not observed in trabecular bone in vivo.

To test whether GRK3 may regulate S1P-stimulated S1PR, our studies utilized SKI to efficiently reduce the active S1P ligand in extended time-course studies and thereby block ligand activation for all S1PR family members expressed on BmMSCs (Fig. 5 and Additional File 5: Fig. S5A and 5B). These results did show that the enhanced proliferation and osteogenic differentiation of Grk3-/- BmMSCs can be reduced to WT levels with effective removal of the S1PR ligand. Of note, we also tested specific S1PR antagonism targeting S1PR1 and S1PR3 [46]. However, we observed BmMSC cellular toxicity in our extended time-course studies while using similar concentrations of vehicle (DMSO) alone that was present in the solubilized S1PR1 and S1PR3 antagonist (VPC23019, Cayman Chemical) group, making this data of receptor-specific antagonism not interpretable. Consequently, our culture studies with BmMSCs and S1PR antagonism could not identify which S1PR subtype expressed on BmMSCs elicit the enhanced functionality due to concerns about cell viability and experimental rigor.

GRK3 is a ubiquitously expressed kinase that regulates a number of GPCRs, including parathyroid hormone receptor (PTH-R) [47]. Although our cellular characterization studies suggest loss of GRK3 function affects S1PR signaling leading to enhanced BmMSC functionality ex vivo, we considered GRK3 regulation of parathyroid hormone/parathyroid hormone receptor (PTH/PTH-R), since PTH/PTH-R has been linked to osteoblast differentiation and enhanced hematopoiesis $[48,49]$. However, ligand PTH is not readily available in ex vivo cultures, and PTH-R was absent from a RNA-seq database evaluation of readily expressed GPCRs on (human) BmMSCs (ENCODE GEO accession: GSE90273) [50]. Alternatively, the RNA-seq database showed S1PR expression on BmMSC, and it is well established that S1P is readily available in horse and fetal bovine serum (i.e., BmMSC culture media) [31].

Contrary to our finding, Hosogane et al. proposed CXCL12 regulates bone morphogenetic protein 2-induced osteogenic differentiation of primary mesenchymal stem cells demonstrated in part by treatment with AMD3100 (CXCR4 antagonist) to show reduction of osteogenic differentiation [51]. Our functional tests with CXCL12 stimulation or CXCR4 signaling inhibition with AMD3100 resulted in no effect (Additional File 3: Fig. S3). One explanation for differences between our data is that CXCR4 is detected on human BmMSCs [52, 53] but less so on murine BmMSCs cultured in vitro [54]. Other possible explanations for outcome differences may be that the Hosogane et al. MSC cultures were different based on isolation technique, cell surface marker expression, differences in AMD3100 concentration, or a combination of these variables.

To investigate whether the enhanced functionalities of Grk3-/- BmMSCs were due to changes in S1PR signaling, we tested the ERK signaling pathway since previous studies suggest ERK activation promotes both mesenchymal stem cell [33] and pre-osteoblastic cell line [34] osteogenic differentiation, as well as mesenchymal stem cell proliferation [12]. Our previous work has shown GRK deficiency elicits sustained ERK signaling due to prolonged GPCR surface expression and failure to desensitize ligand-GPCR stimulation [4]; therefore, 
we hypothesized loss of GRK3 in BmMSCs may elicit sustained ERK activation through S1P/S1PR ligation. Our results show stimulation with S1P prolongs Grk3/- BmMSC ERK1/2 signaling (Fig. 6) and thus suggest S1P-ligand-induced signaling of Grk3-/- BmMSCs may promote enhanced cell functions mediated through the ERK1/2 signaling pathway.

S1PR1 and S1PR3 have been shown to stimulate BmMSC function [36], but S1PR1-mediated enhanced proliferation has been demonstrated in adipose-derived MSCs [12]. Thus, we focused our receptor signaling regulation studies on S1PR1 to determine whether GRK3 enhances recruitment of $\beta$-arrestin-2, a protein necessary for GPCR internalization and another pathway of GPCR regulation in addition to receptor desensitization by GRKs. Previous studies have shown GRK2, which shares high homology with GRK3, phosphorylates the C-terminus of S1PR1 $[55,56]$, and activated S1PR1 recruits $\beta$-arrestin-2 for receptor internalization [56, 57]. Furthermore, cells deficient in GRK2 have high levels of surface S1PR1 [39]. Consequently, we compared GRK2 as a positive control for our modified-TANGO assay. We demonstrate GRK3 enhances $\beta$-arrestin-2 recruitment to the C-terminus of S1PR1, as does GRK2 (Fig. 7A). Furthermore, BmMSCs deficient in GRK3 had decreased S1PR1 internalization (i.e., more surface expression) (Fig. 7B). Thus, we propose loss of GRK3 affects S1PR1 regulation on the BmMSC by impairing S1PR desensitization, prolonging S1PR internalization leading to enhanced surface receptor expression and ligand activation with S1P that in turn sustains late-phase ERK1/2 activation (Fig. 8).

These data show increased MSC osteogenic potential and proliferative growth by targeting the GRK3-mediated GPCR signaling pathway S1P/S1PR. Because the GPCR superfamily has been one of the more successfully targeted class of receptors for drug therapy [58], GPCR antagonism of a receptor that GRK3 regulates or direct kinase inhibition of GRK3 is readily achievable. Indeed, several antagonists of the S1PR signaling pathway are under study for preclinical and clinical use [2]. Thus, future directions in GRK3 signaling in stem cell and bone biology may provide mechanistic insight and therapeutic advancement for several clinical diseases and treatment indications, including but not limited to metabolic bone disease, stem cell transplantation, healing of fracture, and/or in vivo scaffolding.

\section{Conclusion}

In summary, our study reveals how Grk3-/- BmMSCs have enhanced functions of osteogenic differentiation and proliferation that is attributed to altered S1P/S1PR (Fig. 7A). We demonstrate GRK3 recruits $\beta$-arrestin-2, a protein necessary for receptor internalization, to the

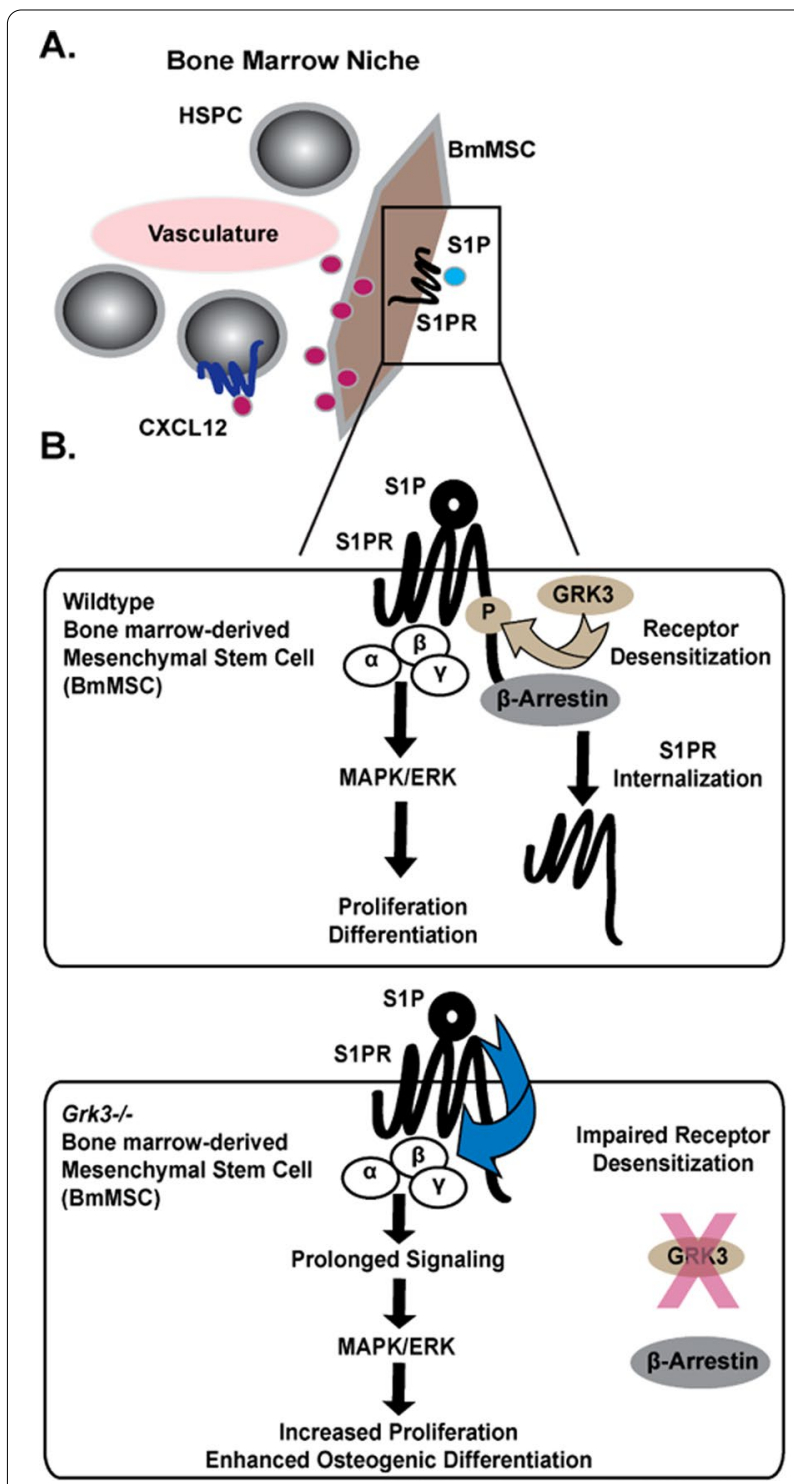

Fig. 8 Proposed model for GRK3-deficient BmMSCs within the niche. (A) Our studies suggest BmMSCs deficient in GRK3 secrete more CXCL12 and proliferate more rapidly, which may increase support to hematopoietic stem and progenitor cell (HSPC) development. (B, top) We propose GRK3 desensitizes S1PR and recruits $\beta$-arrestin to affect ERK1/2 signaling and receptor internalization. (B, bottom) Grk3-/- BmMSCs have enhanced functions of proliferation and osteogenic differentiation, and this may be mediated through decreased S1PR1 internalization (i.e., more surface expression) and prolonged late-phase ERK1/2 activation

C-terminus of S1PR1, and BmMSCs lacking GRK3 regulation have impaired S1PR1 internalization and prolonged ERK1/2 signaling (Fig. 7B). Our work suggests GRK3 regulates S1PR on BmMSCs, and we propose lack of such regulation affects BmMSC functionality. This research could have future implications 
for cellular-based treatment of cancer, autoimmunity, or fracture.

\begin{abstract}
Abbreviations
ALP: Alkaline phosphatase; BmMSC: Bone marrow-derived mesenchymal stem cell; CCK-8: Cell counting kit-8; CEM: Complete expansion media; CIM: Complete isolation media; CXCL12: C-X-C motif chemokine ligand 12; CXCR4: C-X-C chemokine receptor type 4; DMSO: Dimethyl sulfoxide; ERK: Extracellular-related kinase; FBS: Fetal bovine serum; GRK2: G protein-coupled receptor kinase 2; GRK3: G protein-coupled receptor kinase 3; GRK3-KD: G proteincoupled receptor kinase 3 knock-down; GPCR: G protein-coupled receptor; HS: Horse serum; HSPC: Hematopoietic stem and progenitor cell; IMDM: Iscove's modified Dulbecco's medium; LSK: Lin(-) Sca-1(+) c-Kit(+) hematopoietic stem and progenitor cells; PTH: Parathyroid hormone; PTH-R: Parathyroid hormone receptor; qRT-PCR: Quantitative reverse transcription polymerase chain reaction; S1P: Sphingosine-1-phosphate; S1PR: Sphingosine-1-phosphate receptor; SKI: Sphingosine kinase inhibitor; WT:Wild type; $\mu \mathrm{CT}$ : Microcomputed tomography.
\end{abstract}

\section{Supplementary Information}

The online version contains supplementary material available at https://doi. org/10.1186/s13287-022-02715-4.

Additional file 1: Fig. S1. Mouse mesenchymal stem cell marker panel. Representative WT (top) and Grk3-/- (bottom) BmMSCs expression of positive markers CD106, CD73, CD44, CD29, Sca1 and negative hematopoietic markers CD45 and CD1 1b (macrophage). Data plotted as percent (normalized to mode)

Additional file 2: Fig. S2. CD73 expression on BmMSCs. WT $(n=4)$ and Grk3-/- $(n=4)$ BmMSCs expression of positive CD73 for passages 8-11 of 4 independent isolated batches for each genotype

Additional file 3: Fig. S3. BmMSC proliferation was not affected by CXCL12 stimulation or CXCR4 signaling inhibition with AMD3100. (A) Cellular proliferation was not enhanced in the presence of $C X C L 12$, a CXCR4 agonist, at various concentrations, and (B) cellular proliferation was not reduced in the presence of AMD3100, a CXCR4 antagonist at various concentrations. Data represent mean $\pm \mathrm{SEM}, n=3$

Additional file 4: Fig. S4. WT and Grk3-/- BmMSCs have comparable sphingosine kinase activity WT and Grk3-/- BmMSCs were treated with fluorescein-labeled sphingosine to assess the BmMSC ability to convert sphingosine to active ligand sphingosine-1-phosphate (S1P) through sphingosine kinase (SphK) activity. WT and Grk3-/-BmMSC converted sphingosine into S1P (i.e., SphK activity) at comparable levels. Data represent mean $\pm \mathrm{SEM}, n=3$

Additional file 5: Fig. S5. WT and Grk3-/- BmMSCs express S1PR1. (A) Immunoblot detection of S1PR1 from both WT and Grk3-/- BmMSC lysates, and (B) flow cytometry detection of surface S1PR1 (PE-conjugated) on Sca1+ (APC-conjugated) WT and Grk3-/- BmMSCs, passages 11, 12

\section{Acknowledgements}

We would like to acknowledge our use of The UNC Flow Cytometry Core Facility (supported in part by P30 CA016086 Cancer Center Core Support Grant to the UNC Lineberger Comprehensive Cancer Center), The UNC Hooker Imaging Core, and the ENCODE Consortium using Dr. Thomas Gingeras' (Cold Spring Harbor Labs) RNA-seq database of human BmMSCs. We would like to thank Dr. Bryan Roth (UNC) for the TANGO constructs and Dr. Robert Lefkowitz (Duke) for the Grk3-/- mouse strain. We would like to thank Li Xu (Duke) and Dr. Anthony Filiano (Duke) for qRT-PCR technical support.

\section{Authors' contributions}

JMB was responsible for conception and design, financial support, collection and/or assembly of data, data analysis and interpretation, and manuscript writing. RGT, DSS, JK, YR, TFH, DA, and CTR were responsible for the collection and/or assembly of data, data analysis, and interpretation. BA, RRR, and DM were responsible for collection and/or assembly of data. AME was responsible for statistical analyses review. MJH, JR, NLA, and MJB were responsible for conception and design. TKT was responsible for conception and design, financial support, collection and/or assembly of data, data analysis and interpretation, manuscript writing and final approval of manuscript. EMR was responsible for writing collection and/or assembly of data, data analysis and interpretation, manuscript writing.

\section{Funding}

Funding was provided by the National Heart, Lung, and Blood Institute (NHLBI) of the National Institutes of Health under Award No. F31HL128029, the National Institute of Arthritis and Musculoskeletal and Skin Diseases (NIAMS) under Award No. R03AR059286, and the National Institute of Allergy and Infectious Diseases (NIAID) under Award No. K08AI070684.

\section{Availability of data and materials}

The data obtained in these studies is contained within the manuscript and Additional files 1, 2, 3, 4, and 5 .

\section{Declarations}

\section{Ethics approval and consent to participate}

Mice were used under standard IACUC-approved protocols in the AAALACaccredited vivarium of UNC, and care of animals was in accordance with institutional guidelines.

\section{Consent for publication}

Not applicable.

\section{Competing interests}

The authors declare that they have no competing interests.

\section{Author details}

${ }^{1}$ Department of Microbiology and Immunology, University of North Carolina at Chapel Hill, Chapel Hill, NC, USA. ${ }^{2}$ Thurston Arthritis Research Center, University of North Carolina at Chapel Hill, Chapel Hill, USA. ${ }^{3}$ Department of Medicine, Division of Rheumatology and Immunology, Duke University, 200 Trent Dr., DUMC 3874, Durham, NC, USA. ${ }^{4}$ Department of Orthopaedic Surgery, Duke Orthopaedic Cellular, Developmental and Genome Laboratories, Duke University School of Medicine, Durham, NC, USA. ${ }^{5}$ Department of Chemistry, University of North Carolina at Chapel Hill, Chapel Hill, NC, USA. ' Department of Biomedical Engineering at Stony, Brook University, Stony Brook, NY, USA. ${ }^{7}$ Department of Medicine, University of North Carolina at Chapel Hill, Chapel Hill, NC, USA. ${ }^{8}$ School of Medicine, Duke University, 152 Edwin L. Jones Building, 207 Research Drive, Durham, NC 27710, USA.

Received: 8 March 2021 Accepted: 22 December 2021

Published online: 29 January 2022

\section{References}

1. Bernardo ME, Fibbe WE. Mesenchymal stromal cells: sensors and switchers of inflammation. Cell Stem Cell. 2013;13(4):392-402.

2. Brozowski JM, Billard MJ, Tarrant TK. Targeting the molecular and cellular interactions of the bone marrow niche in immunologic disease. Curr Allergy Asthma Rep. 2014;14(2):402.

3. Dar A, Kollet O, Lapidot T. Mutual, reciprocal SDF-1/CXCR4 interactions between hematopoietic and bone marrow stromal cells regulate human stem cell migration and development in NOD/SCID chimeric mice. Exp Hematol. 2006;34(8):967-75.

4. Tarrant TK, Billard MJ, Timoshchenko RG, McGinnis MW, Serafin DS, Foreman O, et al. G protein-coupled receptor kinase-3-deficient mice exhibit WHIM syndrome features and attenuated inflammatory responses. J Leukoc Biol. 2013;94(6):1243-51.

5. Balabanian K, Levoye A, Klemm L, Lagane B, Hermine O, Harriague J, et al. Leukocyte analysis from WHIM syndrome patients reveals a pivotal role for GRK3 in CXCR4 signaling. J Clin Invest. 2008;118(3):1074-84. 
6. Peppel K, Boekhoff I, McDonald P, Breer H, Caron MG, Lefkowitz RJ. G protein-coupled receptor kinase 3 (GRK3) gene disruption leads to loss of odorant receptor desensitization. J Biol Chem. 1997;272(41):25425-8.

7. Doze VA, Perez DM. GPCRs in stem cell function. Prog Mol Biol Transl Sci. 2013;115:175-216

8. Marycz K, Smieszek A, Jelen M, Chrzastek K, Grzesiak J, Meissner J. The effect of the bioactive sphingolipids S1P and C1P on multipotent stromal cells-new opportunities in regenerative medicine. Cell Mol Biol Lett. 2015;20(3):510-33.

9. Marycz K, Krzak J, Maredziak M, Tomaszewski KA, Szczurek A, Moszak K. The influence of metal-based biomaterials functionalized with sphingosine-1-phosphate on the cellular response and osteogenic differentaion potenial of human adipose derived mesenchymal stem cells in vitro. J Biomater Appl. 2016;30(10):1517-33.

10. Hashimoto Y, Matsuzaki E, Higashi K, Takahashi-Yanaga F, Takano A, Hirata $\mathrm{M}$, et al. Sphingosine-1-phosphate inhibits differentiation of $\mathrm{C} 3 \mathrm{H} 10 \mathrm{~T} 1 / 2$ cells into adipocyte. Mol Cell Biochem. 2015;401(1-2):39-47.

11. Lu W, Xiu X, Zhao Y, Gui M. Improved Proliferation and Differentiation of Bone Marrow Mesenchymal Stem Cells Into Vascular Endothelial Cells With Sphingosine 1-Phosphate. Transplant Proc. 2015;47(6):2035-40.

12. Shen H, Zhou E, Wei X, Fu Z, Niu C, Li Y, et al. High density lipoprotein promotes proliferation of adipose-derived stem cells via S1P1 receptor and Akt, ERK1/2 signal pathways. Stem Cell Res Ther. 2015;6:95.

13. Nemeth K, Mayer B, Sworder BJ, Kuznetsov SA, Mezey E. A practical guide to culturing mouse and human bone marrow stromal cells. Curr Protoc Immunol. 2013;102:Unit 22F 12.

14. Peister A, Mellad JA, Larson BL, Hall BM, Gibson LF, Prockop DJ. Adult stem cells from bone marrow (MSCs) isolated from different strains of inbred mice vary in surface epitopes, rates of proliferation, and differentiation potential. Blood. 2004;103(5):1662-8.

15. Sen B, Styner M, Xie Z, Case N, Rubin CT, Rubin J. Mechanical loading regulates NFATC1 and beta-catenin signaling through a GSK3beta control node. J Biol Chem. 2009;284(50):34607-17.

16. Billard MJ, Fitzhugh DJ, Parker JS, Brozowski JM, McGinnis MW Timoshchenko RG, et al. G Protein Coupled Receptor Kinase 3 Regulates Breast Cancer Migration, Invasion, and Metastasis. PLoS One. 2016;11(4):e0152856.

17. Maxwell S, Delaney H. Designing Experiments and Analyzing Data: A Model Comparison Perspective. New York, NY: Psychology Press; 2004

18. Sidak Z. Rectangular confidence regions for the means of multivariate normal distributions. J Am Stat Assoc. 1967;62(318):626-33.

19. Tukey JW. The Problem of Multiple Comparisons. Princeton University1953.

20. Dunnett CW. A multiple comparison procedure for comparing several treatments with a control. J Am Stat Assoc. 1955;50(272):1096-121.

21. Abbuehl JP, Tatarova Z, Held W, Huelsken J. Long-Term Engraftment of Primary Bone Marrow Stromal Cells Repairs Niche Damage and Improves Hematopoietic Stem Cell Transplantation. Cell Stem Cell. 2017;21 (2):24155 e6.

22. Greenbaum A, Hsu YM, Day RB, Schuettpelz LG, Christopher MJ, Borgerding JN, et al. CXCL12 in early mesenchymal progenitors is required for haematopoietic stem-cell maintenance. Nature. 2013;495(7440):227-30.

23. Ding L, Morrison SJ. Haematopoietic stem cells and early lymphoid progenitors occupy distinct bone marrow niches. Nature. 2013:495(7440):231-5

24. Mendez-Ferrer S, Michurina TV, Ferraro F, Mazloom AR, Macarthur BD, Lira SA, et al. Mesenchymal and haematopoietic stem cells form a unique bone marrow niche. Nature. 2010:466(7308):829-34.

25. Le Blanc K, Samuelsson H, Gustafsson B, Remberger M, Sundberg B, Arvidson J, et al. Transplantation of mesenchymal stem cells to enhance engraftment of hematopoietic stem cells. Leukemia. 2007;21(8):1733-8.

26. Maitra B, Szekely E, Gjini K, Laughlin MJ, Dennis J, Haynesworth SE, et al. Human mesenchymal stem cells support unrelated donor hematopoietic stem cells and suppress T-cell activation. Bone Marrow Transplant. 2004;33(6):597-604.

27. Aubin JE. Regulation of osteoblast formation and function. Rev Endocr Metab Disord. 2001;2(1):81-94.

28. Birmingham E, Niebur GL, McHugh PE, Shaw G, Barry FP, McNamara LM. Osteogenic differentiation of mesenchymal stem cells is regulated by osteocyte and osteoblast cells in a simplified bone niche. Eur Cell Mater. 2012:23:13-27.
29. Luo J, Busillo JM, Stumm R, Benovic JL. G Protein-Coupled Receptor Kinase 3 and Protein Kinase C Phosphorylate the Distal C-Terminal Tail of the Chemokine Receptor CXCR4 and Mediate Recruitment of beta-Arrestin. Mol Pharmacol. 2017;91 (6):554-66.

30. Freitas C, Wittner M, Nguyen J, Rondeau V, Biajoux V, Aknin ML, et al. Lymphoid differentiation of hematopoietic stem cells requires efficient $\mathrm{Cxcr} 4$ desensitization. J Exp Med. 2017;214(7):2023-40.

31. Edsall LC, Spiegel S. Enzymatic measurement of sphingosine 1-phosphate. Anal Biochem. 1999;272(1):80-6.

32. Sassoli C, Frati A, Tani A, Anderloni G, Pierucci F, Matteini F, et al. Mesenchymal stromal cell secreted sphingosine 1-phosphate (S1P) exerts a stimulatory effect on skeletal myoblast proliferation. PLoS One. 2014;9(9):e108662.

33. Jaiswal RK, Jaiswal N, Bruder SP, Mbalaviele G, Marshak DR, Pittenger MF. Adult human mesenchymal stem cell differentiation to the osteogenic or adipogenic lineage is regulated by mitogen-activated protein kinase. J Biol Chem. 2000;275(13):9645-52.

34. Ge C, Yang Q, Zhao G, Yu H, Kirkwood KL, Franceschi RT. Interactions between extracellular signal-regulated kinase $1 / 2$ and p38 MAP kinase pathways in the control of RUNX2 phosphorylation and transcriptional activity. J Bone Miner Res. 2012;27(3):538-51.

35. Yang L, Chang N, Liu X, Han Z, Zhu T, Li C, et al. Bone marrow-derived mesenchymal stem cells differentiate to hepatic myofibroblasts by transforming growth factor-beta1 via sphingosine kinase/sphingosine 1-phosphate (S1P)/S1P receptor axis. Am J Pathol. 2012;181(1):85-97.

36. Kong $Y$, Wang $H$, Lin T, Wang S. Sphingosine-1-phosphate/S1P receptors signaling modulates cell migration in human bone marrow-derived mesenchymal stem cells. Mediators Inflamm. 2014;2014:565369.

37. Chang N, Xiu L, Li L. Sphingosine 1-phosphate receptors negatively regulate collagen type I/III expression in human bone marrow-derived mesenchymal stem cell. J Cell Biochem. 2014;115(2):359-67.

38. Kroeze WK, Sassano MF, Huang XP, Lansu K, McCorvy JD, Giguere PM, et al. PRESTO-Tango as an open-source resource for interrogation of the druggable human GPCRome. Nat Struct Mol Biol. 2015;22(5):362-9.

39. Arnon TI, Xu Y, Lo C, Pham T, An J, Coughlin S, et al. GRK2-dependent S1PR1 desensitization is required for lymphocytes to overcome their attraction to blood. Science. 2011;333(6051):1898-903.

40. Bara JJ, Richards RG, Alini M, Stoddart MJ. Concise review: Bone marrow-derived mesenchymal stem cells change phenotype following in vitro culture: implications for basic research and the clinic. Stem Cells. 2014;32(7):1713-23

41. Bernardo ME, Fibbe WE. Mesenchymal stromal cells and hematopoietic stem cell transplantation. Immunol Lett. 2015;168(2):215-21.

42. Meriane M, Duhamel S, Lejeune L, Galipeau J, Annabi B. Cooperation of matrix metalloproteinases with the RhoA/Rho kinase and mitogenactivated protein kinase kinase-1/extracellular signal-regulated kinase signaling pathways is required for the sphingosine-1-phosphateinduced mobilization of marrow-derived stromal cells. Stem Cells. 2006;24(11):2557-65.

43. Jung S, Panchalingam KM, Rosenberg L, Behie LA. Ex vivo expansion of human mesenchymal stem cells in defined serum-free media. Stem Cells Int. 2012;2012:123030.

44. Suto EG, Mabuchi Y, Suzuki N, Suzuki K, Ogata Y, Taquchi M, et al. Prospectively isolated mesenchymal stem/stromal cells are enriched in the CD73+ population and exhibit efficacy after transplantation. Sci Rep. 2017;7(1):4838.

45. Spurney RF. Regulated expression of $\mathrm{G}$ protein-coupled receptor kinases (GRK's) and beta-arrestins in osteoblasts. Calcif Tissue Int. 2003;73(2):153-60.

46. Davis MD, Clemens JJ, Macdonald TL, Lynch KR. Sphingosine 1-phosphate analogs as receptor antagonists. J Biol Chem. 2005;280(11):9833-41.

47. Flannery PJ, Spurney RF. Domains of the parathyroid hormone (PTH) receptor required for regulation by $\mathrm{G}$ protein-coupled receptor kinases (GRKs). Biochem Pharmacol. 2001;62(8):1047-58.

48. Calvi LM, Adams GB, Weibrecht KW, Weber JM, Olson DP, Knight MC, et al. Osteoblastic cells regulate the haematopoietic stem cell niche. Nature. 2003:425(6960):841-6.

49. Calvi LM. Osteoblastic activation in the hematopoietic stem cell niche. Ann N Y Acad Sci. 2006:1068:477-88.

50. Consortium EP. An integrated encyclopedia of DNA elements in the human genome. Nature. 2012;489(7414):57-74. 
51. Hosogane N, Huang Z, Rawlins BA, Liu X, Boachie-Adjei O, Boskey AL, et al. Stromal derived factor-1 regulates bone morphogenetic protein 2-induced osteogenic differentiation of primary mesenchymal stem cells. Int J Biochem Cell Biol. 2010;42(7):1132-41.

52. Son BR, Marquez-Curtis LA, Kucia M, Wysoczynski M, Turner AR, Ratajczak $J$, et al. Migration of bone marrow and cord blood mesenchymal stem cells in vitro is regulated by stromal-derived factor-1-CXCR4 and hepatocyte growth factor-c-met axes and involves matrix metalloproteinases. Stem Cells. 2006;24(5):1254-64.

53. Kortesidis A, Zannettino A, Isenmann S, Shi S, Lapidot T, Gronthos S. Stromal-derived factor-1 promotes the growth, survival, and development of human bone marrow stromal stem cells. Blood. 2005;105(10):3793-801.

54. Chen W, Li M, Cheng H, Yan Z, Cao J, Pan B, et al. Overexpression of the mesenchymal stem cell $\mathrm{Cxcr} 4$ gene in irradiated mice increases the homing capacity of these cells. Cell Biochem Biophys. 2013;67(3):1181-91.

55. Watterson KR, Johnston E, Chalmers C, Pronin A, Cook SJ, Benovic JL, et al. Dual regulation of EDG1/S1P(1) receptor phosphorylation and internalization by protein kinase $\mathrm{C}$ and $\mathrm{G}$-protein-coupled receptor kinase 2. J Biol Chem. 2002;277(8):5767-77.

56. Oo ML, Thangada S, Wu MT, Liu CH, Macdonald TL, Lynch KR, et al. Immunosuppressive and anti-angiogenic sphingosine 1-phosphate receptor-1 agonists induce ubiquitinylation and proteasomal degradation of the receptor. J Biol Chem. 2007;282(12):9082-9.

57. Sic H, Kraus H, Madl J, Flittner KA, von Munchow AL, Pieper K, et al. Sphingosine-1-phosphate receptors control B-cell migration through signaling components associated with primary immunodeficiencies, chronic lymphocytic leukemia, and multiple sclerosis. J Allergy Clin Immunol. 2014;134(2):420-8.

58. Lagerstrom MC, Schioth HB. Structural diversity of G protein-coupled receptors and significance for drug discovery. Nat Rev Drug Discov. 2008;7(4):339-57.

59. Jiang D, Sims CE, Allbritton NL. Microelectrophoresis platform for fast serial analysis of single cells. Electrophoresis. 2010;31(15):2558-65.

\section{Publisher's Note}

Springer Nature remains neutral with regard to jurisdictional claims in published maps and institutional affiliations.

Ready to submit your research? Choose BMC and benefit from:

- fast, convenient online submission

- thorough peer review by experienced researchers in your field

- rapid publication on acceptance

- support for research data, including large and complex data types

- gold Open Access which fosters wider collaboration and increased citations

- maximum visibility for your research: over 100M website views per year

At BMC, research is always in progress.

Learn more biomedcentral.com/submissions 